\title{
Interdisciplinaridade sistêmica e estudos geográficos ambientais
}

\section{Systemic interdisciplinarity and geographic environmental studies}

\author{
Rodrigo DUTRA GOMES* \\ Carlos Roberto ESPINDOLA** \\ “ $O$ verdadeiro problema é o seguinte: como a parte da realidade que começa \\ pela consciência pode ajustar-se a outra parte descrita pela física e pela \\ química" \\ Niels Bohr
}

\begin{abstract}
RESUMO
Considerações advindas de desenvolvimentos científicos alimentam hoje a possibilidade de uma maior comunicabilidade e cooperação por entre os conhecimentos, apresentando potencialidades indiscutíveis para os estudos ambientais. A moderna perspectiva sistêmica insere-se neste contexto, consolidando-se como um poderoso instrumento teórico-analítico cujos enriquecimentos sugerem, no período atual, olhares mais flexíveis para dualismos diretamente ligados à temática geográfica em geral e estudos ambientais (sujeito/objeto, qualidade/quantidade, local/global). A partir de um retrospecto histórico de alguns dos avanços e considerações científicas ligados à evolução da perspectiva sistêmica, entendimento da dinâmica física da matéria, da relação sujeito/objeto etc, discorreu-se com algumas das aproximações já realizadas para o entendimento dos sistemas ambientais considerações acerca de tratamentos conjuntos mais adequados das esferas físico-natural e humana.
\end{abstract}

\footnotetext{
* Doutorando da pós-graduação em Geografia IG/UNICAMP. (IG/UNICAMP), dutra@ige.unicamp.br cresp21@hotmail.com

** Professor do Programa de Pós-graduação em Geografia. (IG/UNICAMP), cresp21@hotmail.com. Escrito em 01/2007. Endereço para correspondência: Instituto de Geociências - Secretaria de Pós-Graduação - Rua João Pandiá Calógeras, 51.Universidade Estadual de Campinas - Cidade Universitária “Zeferino Vaz” Distrito de Barão Geraldo - Caixa Postal 6152 CEP 130803-870 Campinas - SP
} 
Palavras-chave: avanços científicos; perspectiva sistêmica; estudos geográfico ambientais.

\begin{abstract}
Considerations resulting from scientific development currently contribute to the possibility of greater communicability and cooperation among areas of knowledge, presenting undeniable possibilities for environmental studies. The modern systemic perspective fits in this context, solidifying itself as a powerful theoretical and analytic instrument whose improvements currently suggest more flexible views of dualisms directly tied to the theme of geography in general and environmental studies (subject/object, quality/ quantity, local/global). Based on a historic survey of some of the scientific considerations and advances related to the evolution of the systemic perspective, understanding of the physical dynamics of matter,
\end{abstract}

the subject/object relationship, etc., some of the approaches already accomplished for understanding environmental systems and considerations regarding the most appropriate groups of approaches to the physical-natural and human environments are covered.

Key words: scientific development; systemic perspective; geographic environmental studies.

\section{Introdução}

As dificuldades dos estudos geográficos ambientais para o tratamento conjunto do dinamismo dos sistemas físico-naturais associados com a complexidade das questões e pertinências humanas são também reflexos de certos dualismos do conhecimento ocidental. Quando filósofos como Bacon, Galileu, Descartes, Newton, Kant e outros formularam as crenças e valores subjacentes à ciência moderna, forneceram também interpretações ideológicas que a sociedade capitalista basearia o seu desenvolvimento a partir de então. Refere-se a princípios como a separação sujeito(Homem)/objeto(Natureza), legislação dos fenômenos, a busca pela simplicidade do objeto, a reversibilidade e não existência do tempo, ordem universal do mundo, objetividade do conhecer etc, são alguns dos princípios científicos primordialmente estabelecidos que, por herança, podem ser encontrados refletidos na cultura do homem ocidental. Contudo, acompanhando os notáveis avanços alcançados pela ciência nos séculos XIX e XX, muitas das dificuldades enfrentadas pela sociedade moderna no período atual, tal como a crise sócio-cultural-ambiental e a relutância por um pensamento e prática interdisciplinar, encontram aí substancial fonte de fundamentação.

A distância estabelecida entre o Homem (humano) e a Natureza promove no homem moderno um sentimento de "não pertencimento e reconhecimento" como parte da Natureza. Distante e externo ao ambiente deixa de reconhecer a si mesmo e ao próximo, alimentando uma postura social omissa com os cidadãos não reconhecendo tanto a Natureza que os sustenta quanto o ambiente social que compõem, constituindo este um dos principais embasamentos para atual crise sócio-cultural-ambiental. No conhecimento científico ela pode ser representada pela clássica dicotomia sujeito/objeto, que se reflete na quase incomunicabilidade entre as áreas humana e física, criando limitações de caráter teórico-metodológico que acabam dificultando uma adequada efetivação das pesquisas interdisciplinares nestes e por estes domínios.

Conjuntamente à constituição das crises da sociedade no último século, desenvolvimentos e aprimoramentos do conhecimento científico possibilitaram conceber os dias atuais como um período de transição de paradigmas. Referenciados nos problemas e desafios da sociedade esses conhecimentos foram convergindo ao longo do século $\mathrm{XX}$ de forma que formaram um corpo de conhecimentos que alimentaram no último quartel do século um 'sentimento’ de possibilidade de realizações de práticas interdisciplinares. Com isso, ainda que de maneira lenta e 
tangencial, a busca por estas práticas foram se intensificando no final do XX, se tornando uma necessidade eminente agora no início do XXI. A consciência da possibilidade e procura por estas práticas não se deram sem embasamentos, se abastecendo de entendimentos advindos de avanços científicos como foram as perspectivas sistêmicas de abordagem.

Com fundos na Teoria Geral dos Sistemas, Cibernética e teoria da informação da década de 50, a perspectiva sistêmica ganhou notoriedade ao ocupar o terreno das 'interrelações’ que se abriu depois da realidade dinâmica apresentada por teorias como biologia, termodinâmica, relatividade e teoria quântica etc. Com amplas aplicações depois da década de 50 as teorias sistêmicas ofereceram, pela linguagem de modelos, ferramentas conceituais e metodológicas aproveitadas por diversos campos, com presença marcante na ciência geográfica e estudos ambientais. Essa teoria e modelos se difundiram nas décadas de 50/60 em resposta ao período desenvolvimentista e planificador do Estado capitalista, oferecendo entendimentos que garantiam princípios de controle e operacionalidade através dos modelos práticos de tratamento e manuseio.

Cabe esclarecer que a corrente analítica que se difundiu depois da segunda metade do século, e que na Geografia foi vivida pela revolução quantitativa e teorética da década de 50, utilizou-se do método hipotético-dedutivo (Popper), pautado na formulação e teste de hipóteses pela elaboração e aplicação de modelos. Sobre o método hipotético-dedutivo subjaz a idéia de que as conjecturas, ou as hipóteses, são, elas mesmas, inevitavelmente mediadas por teorias, paradigmas, programas de pesquisa etc, que dão o tom para a elaboração dos modelos de representação, interpretação e manuseio da realidade (LAKATOS; MUSGRAVE, 1979). Com isso, pode-se dizer que a "riqueza” ou "pobreza” teórica na qual estão baseadas as hipóteses pesarão significativamente na forma e natureza da elaboração e aplicação dos modelos que balizam o entendimento e intervenção prática.

As teorias que passam a ser universalmente reconhecidas, como é a perspectiva sistêmica, são muitas vezes aceitas como paradigmas, guiando a elaboração de modelos e entendimentos muitas vezes de forma inconsciente pelos diversos campos. Frente a esta situação é necessário, tomar o cuidado para que as ênfases dadas às funcionalidades operacionais que os modelos proporcionam não ocasionem a estagnação da criatividade teórica intelectual que, retroativamente, diminuiria o poder do modelo representar e intervir nas problemáticas da realidade. Contra isso, as permanentes capacitações por partes dos pesquisadores em relação aos constantes e ininterruptos avanços teóricos e experimentais da ciência e filosofia são uma das premissas primordiais para a realização de práticas mais efetivas. O reconhecimento de novos e mais amplos entendimentos teórico-epistemológicos tornam-se, assim, fundamental para que haja um real desenvolvimento e aprimoramento operacional dos modelos práticos.

Este artigo vem, assim, no sentido de buscar conectar, de forma direcionada, os estudos geográficos ambientais com alguns dos desenvolvimentos científicos que promoveram no século $\mathrm{XX}$ a constituição de entendimentos mais amplos e flexíveis acerca da dinâmica da matéria e de dualismos fundamentais para o conhecimento moderno. Inseridos numa perspectiva sistêmica, avanços ligados a teorias do caos, a teoria dos sistemas dinâmicos, as estruturas dissipativas, a autopoiese etc, são também os que alimentam uma maior possibilidade de comunicação entre as áreas e efetivação de projetos interdisciplinares. Suas considerações ajudam a flexibilizar, de maneira efetiva, dualidades como o sujeito/objeto, homem/natureza, local/ global, que, por sua vez, fomentam reflexões sobre o ‘distanciamento' e “externalização” do homem em relação à Natureza. Oferecem assim, tanto argumentos que direcionam a conscientizações existenciais do Homem para com a Natureza, si mesmo, e para com o próximo, quanto oferecem norteamentos para a ampliação de abordagens e tratamentos mais adequados em nível metodológico e prático.

Assim, uma interdisciplinaridade sistêmica vem no sentido de contactar entendimentos já disponíveis no contexto científico que ultrapassam fronteiras e dicotomias e, podem oferecer perspectivas mais fecundas que favoreçam a comunicação entre conhecimentos. Com isso, a noção de interdisciplinaridade não será problematizada e discutida no artigo, mas situada na conhecida interpretação de Japiassu (1972) para quem, basicamente interdisciplinaridade refere-se às práticas de interação participativa entre campos de saberes conexos, incluindo a construção e pactação de uma problemática e axiomática teórica comum, definidos em nível hierarquicamente superior de maneira consensual pelo grupo em vista uma finalidade maior. Nesta perspectiva, buscou-se ao longo do artigo entrar em contato com entendimentos mais amplos que permitam vislumbrar maiores aberturas e possibilidade de construção e pactação de axiomáticas teóricas co- 
muns. Acredita-se que, sem tal esforço de contato teórico dificilmente os modelos práticos de intervenção conseguirão se renovar de maneira legitima em ganho de conteúdo, amplitude e flexibilidade necessária para a representação e tratamento dos problemas atuais.

Neste contexto, a crise ambiental que é também cultural, social, econômica, familiar etc reflete-se como um dos problemas gerados pelos princípios modernos e exemplo de desafios que exigem práticas de articulação interdisciplinar de conhecimentos. A problemática envolvida na relação Homem e Natureza (sujeito/objeto) expressa-se de maneira marcante nas dificuldades e limites dos estudos ambientais em tratar de maneira conjunta a confecção e a aplicação de modelos que abranjam tanto os aspectos naturais, quanto os particularmente humanos. Com isso, a busca pelo reconhecimento das bases destas fragmentações e o contato com entendimentos mais amplos são um dos esforços irremediáveis para que haja qualquer reconciliação de conduta.

Neste sentido, a partir de um sucinto resgate das bases constitutivas dos estudos geográficos ambientais, no movimento de formação da ciência e filosofia moderna, discorreu-se sobre as considerações sistêmicas relacionadas à inerência do Humano à Natureza, com vista, concebêlos sob um mesmo foro analítico, sem necessariamente reduzir suas especificidades de manifestação e entendimento. Seguiram-se com a evolução da perspectiva sistêmica, a partir da termodinâmica, teoria quântica, teoria geral dos sistemas, cibernética, teoria do caos, estruturas dissipativas etc, que são acompanhadas de noções como desordem, irreversibilidade, auto-organização, incertezas, instabilidades etc, com reflexões acerca das dualidades e fragmentações do conhecimento científico. Procurou-se em seqüências esclarecer genericamente algumas das aproximações realizadas entre estas noções e entendimentos com os estudos e modelos ambientais, com vista demonstrar a inerência de tais fenômenos nos avanços descritos. Por ainda encontrar-se em fase inicial de reconhecimento conceitual e instrumental, o intuito deste texto foi também o de apresentar aspectos de um rico panorama de reflexões e ferramentas que requerem o despertar à leitura e reflexão por parte dos pesquisadores em geral, principalmente os ligados às questões ambientais, como forma de melhor criar e operacionalizar seus modelos práticos.

\section{Contextualização dos estudos de natureza ambiental}

A visão de mundo na Europa, e na maioria das sociedades, até o fim da Idade Média, era de uma Natureza orgânica, com os fenômenos espirituais e materiais entendidos em dependência recíproca. Essa perspectiva mudou radicalmente nos séculos XVI e XVII, sendo substituída pela noção de "Natureza máquina", ocorrida a partir de mudanças revolucionárias na física e na astronomia (CAPRA, 1982, p.49). A partir da concepção heliocêntrica de Copérnico (1473 - 1543), seguiu-se uma abordagem empírica instituída em linguagem matemática por Galileu (1564-1642), que aliada ao "espírito baconiano" (15611626), voltou este método à ideologia de dominação e transformação da Natureza. Em prosseguimento, Descartes (1596-1650), um dos principais fundadores da ciência moderna, concebendo a Natureza de maneira mecânica destacou a dúvida como elemento primordial da investigação filosófico-científica, propondo um método científico para orientar o conhecimento. Reafirmou a histórica dicotomia entre mente (ego-cogito) e corpo (res-extensa), com o corpo concebido, em conjunto com toda a Natureza, como uma máquina, distanciado do espírito, este, portador da verdade pela razão fundamentada no Deus cristão. Estas constituíram algumas das bases de consolidação do conhecimento científico moderno, que, acompanhava os questionamentos e interesses da nova organização sócioideológico-produtiva que ia se estabelecendo (SANTOS, 1998).

Esta visão foi corroborada por Newton (1643-1727), com a Natureza descrita como uma máquina regida por leis deterministas e dinâmicas ordenadas, elaborando a primeira grande síntese do conhecimento científico, fixando a física como o modelo ideal de cientificidade. A ciência newtoniana teve enorme sucesso nos séculos XVIII e XIX, e mesmo considerando a contínua evolução científica ocorrida neste período, ela foi reconhecida como um padrão a ser seguido, recebendo refinos e, por vezes, sofrendo rupturas (eletrodinâmica, termodinâmica, relatividade, física quântica etc), mas não deixando de permanecer um sólido arcabouço científico. Sob suas bases em E. Kant (17241804) estruturou a possibilidade de constituição de uma autêntica metafísica da natureza, que fundamentava as leis da natureza e possibilitava que as mesmas viabilizassem o conhecimento sobre sua dinâmica (KANT, 1989 apud 
VITTE, 2006, p.36). Estas proposições tiveram grande impacto no século XIX e, entrelaçados com os posteriores avanços da química, biologia, física, medicina etc, firmaram-se, em suas derivações e questionamentos, adesões e contra-correntes, que encontraram, ainda em Kant e depois no movimento romântico, a retomada de uma visão orgânica de Natureza, concebida agora como totalitária e harmoniosa, detendo desenvoltura e possuindo potencialidades. Os pensadores deste movimento, que era também artístico e intelectual, buscavam um híbrido entre ciência-arte-literatura, valorizando temas ligados às emoções, amor, liberdades, religião, individualismo etc.

Neste período foi realçada a importância de se bem localizar e sistematizar o conhecimento da variedade e diversidade geográfica da superfície da Terra com as explorações inter e intracontinentais. Inseridas neste contexto, foram se estabelecendo abordagens contemplativas de estudo da natureza como formas de se estudar a integração e a representação das diversidades dos fenômenos em suas reciprocidades espaciais harmônicas. Essa abordagem acompanhou a tendência artística da época, com pinturas contendo abordagens subjetivas e realçando o tema de contemplação da Natureza, que constituíram pano de fundo para os futuros aprimoramentos da cartografia. Situa-se, neste período, o nascimento de categorias na perspectiva geográfica como espaço, lugar, região, natureza e paisagem, tendo como grande expoente as pesquisas do naturalista A. Humboldt (1769-1859), um dos fundadores da Geografia Moderna.

A abordagem do naturalista alemão encerrava, em si, uma mescla entre racionalismo e empirismo, detendo fundamentos baconianos integrados às filosofias romântica de Goethe e Schelling. Neste período, a natureza foi concebida como um organismo vivo em constante movimento e interação contínua. Definida a partir de uma dialética de forças, o olhar do observador buscaria estabelecer unidades harmônicas em meio a diversidade dos fenômenos que se manifestam espacialmente. Humboldt não se limitava às manifestações das propriedades físico-naturais; ele observava também os fenômenos humanos, relevando as crenças e costumes de sociedades locais, reconhecendo o saber histórico como o aspecto maior da cultura de um povo (VITTE, 2006, p.47-49). Nesta abordagem, as dualidades que caracterizam a modernidade e a Geografia já se encontram presentes, com os domínios físico-naturais e humanos tratados de forma distinta, porém dissolvendo-se num direcionamento de juízo sintético, realizado em cadeias explicativas (GOMES, 2000, p.151). Na seqüência de períodos, destacam-se também as contribuições do russo Dockuchaev (1866-1903), propondo a zonalidade dos solos como resultado das interações, ao longo do tempo, entre os componentes naturais clima, geologia, relevo, solos, vegetação, organismos etc, e que muito mais tarde influenciou a escola russa na elaboração de modelos conceituais como o Geossistema de Sotchava (1977). Sob esse espectro foram se constituindo as bases para uma análise integrada dos componentes da paisagem, que “evoluíram” para posteriores modelos de estudos ambientais.

Localizada na intersecção da relação sociedade/natureza, as dualidades características, tais como racionalismo/empirismo, liberdade/necessidade, ou sujeito/objeto (MORIN, 2001, p.270), encontram-se presentes na Geografia desde a sua fundamentação; porém, nas abordagens iniciais, elas apresentam-se de forma simultâneas, misturadas em proporções variáveis, sem uma aparente contradição, dissolvidas e mescladas numa análise sintética característica de uma totalidade orgânica (GOMES, 2000, p.366). Com a posterior sistematização do positivismo e a derradeira distinção entre ciências física e humana (Dilthey), as dicotomias legadas receberam influências de novas abordagens teórico-metodológicas, que foram vividas e sentidas de diversas formas na Geografia no final do século XIX e começo do XX: darwinista, funcionalista, anarquista, regional, idiográfica, nomotética etc. Como reflexo, as fronteiras erguidas fizeram com que as contradições fossem realçadas, dificultando o confronto de perspectivas e o debate de idéias. Essa situação acabou ficando refletida nas limitações existentes nos estudos ambientais para o tratamento conjunto dos aspectos humanos e físico-naturais nos modelos. A tradição científica analítica de origem cartesiana, fortemente ligada às leis da causalidade, acaba por limitar o levantamento e tratamento de aspectos humanos essenciais, omitindo e reduzindo importantes pertinências responsáveis pela organização espacial, como valores, necessidades, contradições, propósitos, sentimentos, anseios, vivências etc.

Aquela análise integrativa de fundo naturalista ganhou, com o decorrer dos séculos XIX e XX, outras roupagens teórico-metodológicas, enriquecidas pela consolidação de novos campos e abordagens científicas. Neste contexto, a perspectiva sistêmica, com bases modernas teorias da termodinâmica, teoria dos sistemas, cibernética, teoria da informação etc, representa uma destas abordagens de cunho fundamentalmente interdisciplinar, que constituiu, 
a partir das várias adesões nos diversos campos, uma sólida perspectiva para o tratamento científico. Tais ensinamentos foram amplamente aplicados na compreensão de fenômenos físicos, biológicos e humanos. Para os estudos de caráter ambiental em geral a abordagem sistêmica, por focarem nas inter-relações dos fenômenos, concebendo a realidade numa cadeia infinita de sub e supra-sistemas interatuantes, passaram a nortear de maneira tanto consciente, quanto inconsciente, as aplicações dos estudos ambientais.

Aplicada aos estudos ambientais a análise sistêmica carregou como herança, os reducionismos e limitações da cientificidade analítica para a representação dos aspectos humanos nos modelos aplicado. Assim, mesmo que muitas de suas manifestações pudessem ser descritas de maneira analítica, nuanças singulares ainda não poderiam ficando omitidas e reduzidas, requerendo muito mais formas de representações mais adequada aos fenômenos e conduta humana. Se essa dificuldade não é tanto de caráter conceitual, acaba por ficar realçada nos limites metodológicos quando se procuram tratar, de maneira conjunta, as informações humanas e físico-naturais. Essas restrições vêm diminuir o poder de representação e diagnóstico dos problemas, necessidades, restrições e potencialidades dos lugares e ambientes, comprometendo a execução e a capacidade prognostica dos fenômenos.

A partir da evolução do conhecimento experimental e teórico no século XX, foi constituído um amplo contexto alimentado de discussões e interpretações referente a aspectos basilares do conhecimento científico. Muitas dessas considerações dizem respeito a questões interdisciplinares que subjazem as fronteiras duais do conhecimento. Podem, assim, oferecer potencialidades para a diminuição da distância entre os conhecimentos científicos e humanísticos. A constituição de campos como a termodinâmica, física quântica, teoria dos sistemas, cibernética, além da consolidação de noções como caos, sistemas dinâmicos, estruturas dissipativas, auto-organização, autopoiese etc, trazem substanciais considerações para a possibilidade de um pensamento mais flexível acerca dos dualismos históricos (necessidade/liberdade, ordem/desordem, quantitativo/qualitativo, sujeito/objeto).

Essas considerações dizem respeito a aspectos diretamente ligados ao dinamismo dos sistemas ambientais, com entendimentos, ferramentas e conceitos que permitem refinar teorias e modelos frente às tendências científicas, que, por sua vez, ampliaram os conhecimentos pela qual os estudos aplicados se basearão. Neste caminho, uma das buscas consiste em conseguir fundamentos teóricometodológicos que orientem e auxiliem condutas mais adequadas para levantamentos, trocas e tratamentos conjunto das informações humana e físico-natural.

Inserido numa perspectiva sistêmica, a partir da contextualização desses avanços, julgou-se oportuno arrolar considerações realizadas por alguns filósofos e cientistas acerca de aspectos do entendimento da dinâmica física da matéria e da relação homem/natureza (sujeito/objeto). Nos estudos ambientais a busca por tratamento adequado entre as esferas físico-natural e humano é um questionamento há muito presente. Isso favorece os contatos, adequações e refinamentos em relação aos avanços científicos, visto que, já apresentam disponíveis considerações pertinentes sobre a procura de abordagens mais amplas e flexíveis para o tratamento conjunto das esferas que constituem a natureza e a sociedade humana. Isso oferece maior segurança de aproximação em vista pautarem-se em proposições já conhecidas e testadas. Mesmo presentes já há algum tempo no cenário científico, os aprimoramentos teórico-experimentais somente aos poucos vão sendo sentidos pelas diversas disciplinas que se utilizam da abordagem sistêmica, revelando-se um contexto com possibilidade de realização de várias leituras, interpretações e adaptações.

Para os estudos geográficos ambientais as aproximações se deram pelo reconhecimento empírico e lógico-formal dos sistemas físicos ambientais como representantes dos fenômenos ligados às incertezas, instabilidades, caos, auto-organização etc, adequando refinamentos conceituais e instrumentais. Contudo, ainda é pouca a atenção dada às possíveis repercussões epistemológicas trazidas por este contexto para a ampliação do arcabouço teórico dos modelos ambientais. Pode-se, por exemplo, adiantar que estas visões não sugerem a elaboração de modelos globalizantes, pois, ao contrário, os avanços científicos acabam por realçar as limitações analíticas e sistêmicas na representação de nuanças essenciais dos fenômenos humanos. Reconhecimentos deste tipo, fundado e contextualizado em bases científicas, pode ajudar a orientar abordagens detendo abertura para articulações entre distintos conhecimentos em objetivos comuns, em projeto a comunicações mais efetivas para a resolução dos problemas da sociedade. 


\section{Evolução da perspectiva sistêmica}

A partir da constituição da ciência do calor e a formulação das leis da termodinâmica, na segunda metade do séc. XIX, o pressuposto de ordem soberana do determinismo mecanicista abre espaço para a inserção da desordem, concebida enquanto estado energético de num sistema, na descrição do universo físico. A $1^{\text {a }}$ lei da termodinâmica afirma que a energia total do Universo é constante. A $2^{\mathrm{a}}$ Lei refere-se à alteração de seu estado pela dinâmica de inter-relações entre os corpos, se tratando da quantidade de energia livre disponível no sistema à realização de trabalho; que vai, de um potencial, para um degradado, perdido pela dissipação em calor, forma mais degradada, denominada de entropia, que a energia pode ser apresentada na natureza. É referenciada na $2^{\mathrm{a}}$ lei que se concebe a idéia de que, uma vez gasta, ou dissipada, a energia não pode ser reutilizada, caracterizando um processo irreversível que se orienta em direção única, inserindo o questionamento da unidirecionalidade do Tempo.

Entretanto, o Tempo ainda permaneceu reversível, uma vez que, a $2^{\mathrm{a}}$ Lei é uma lei estatística, com a "máxima" probabilidade de um sistema isolado atingir a entropia, a desordem máxima no sistema: como a falta de combustível e paragem do motor caso se utilize e não abasteça um automóvel. Contudo, em relação à sua descrição física, ainda permanece, mesmo que ínfima, a possibilidade de uma descrição simétrica e reversível do processo de dissipação do calor (CAPRA, 1982, p.68). As sociedades atuais são reconhecidamente grandes produtoras de entropia para a sua manutenção e reprodução, e, longe de apenas considerar somente seu sentido pejorativo, é reconhecidamente fonte de preocupação em vista à irreversibilidade dos processos de degradação já gerados. Com escalas temporais rítmicas próprias, apenas espera-se o momento (20-30 anos?) de começar a observar-se retroação dos danos no equilíbrio ecossistêmico global.

$\mathrm{O}$ aprimoramento dos conhecimentos a respeito das partículas atômicas exigiu ajustes das antigas formas de descrições clássicas à situação fenomenal e descritiva encontrada. O princípio da incerteza de Heisenberg e o da complementaridade de Bohr são representantes dessas adequações. No primeiro caso, ficou constatado que o próprio ato de observar uma partícula atômica (o elétron) acabava por interferir em sua medição, tornando-a impossível de ser observada objetivamente em sua posição e velocidade.
Na mecânica de Einstein e de Newton estas duas propriedades poderiam ser especificadas em qualquer instante de tempo, o que não ocorreu com a mecânica quântica, que necessitou introduzir o conceito de probabilidade na formulação teórica deste conhecimento, no sentido de que o elétron possui a possibilidade, ou probabilidade, de estar em determinado lugar, porém este é sempre incerto. Não é possível mais falar em objetividade absoluta na experimentação científica, com a interferência do sujeito e a incerteza ligada à probabilidade encontra-se embutida na teoria quântica (HEISENBERG, 1981, p.132-133).

No caso da complementaridade, a antinomia observada na constituição da partícula, entre onda/corpúsculo ou energia/matéria, não sugeriu a Bohr a separação e favorecimento de um dos termos. Para o cientista dinamarquês a dualidade não dizia respeito à realidade da partícula, em si mesma, pois esta seria indivisível, total. Numa atitude "realista", acreditando na existência de uma realidade independente do sujeito, concebe que a propriedade da partícula seria especificada pela pergunta, ou método, de questionamento que seria feito ao objeto: questionado como onda obtém-se freqüências, como partícula obtémse corpúsculos. Considerou que a dualidade onda e corpúsculo era uma antinomia somente descritiva, e que as descrições poderiam ser concebidas como noções complementares. Assim, o conhecimento da posição da partícula pode ser complementada pelo conhecimento de sua velocidade, porém, o conhecimento de uma das propriedades causa inevitavelmente a interferência na concepção da outra, em concordância com o princípio da incerteza. Esse problema levou Heisenberg a concluir que, tanto no nível atômico, quanto para a ciência em geral, não se pode separar o objeto do seu método. O conhecimento se refere sempre sobre descrições da realidade e não dela, em si mesma, como aliás, filosoficamente foi sistematizado em Kant no XVIII, e na década de 30 do XX, reconhecido na experimentação científica (CAPRA, 1982, p.75). Outro aspecto significante foi a revelação científica da interconectividade dos corpos. Ficou entendida que, não se pode decompor a matéria em partes com existências independentes uma das outras, pois, em seu nível fundamental, não ais quaisquer elementos isolados, mas, sim, uma complexa teia de interconexões que compõem e ressaltam a unicidade da Natureza.

Acompanhando essa tendência inter-conectiva, surgiram no mesmo período, as teorias sistêmicas, enriquecidas com a Teoria Geral dos Sistemas (TGS), de Bertalanffy 
(1973), e a Cibernética de Wiener (1954). Suas contribuições auxiliaram a formulação, em termos científicos modernos, dos princípios que norteiam o entendimento dos sistemas em geral. Foram constituídas a partir da década de 30, ganhando mais fôlego após a Segunda Guerra Mundial. Considerados como campos fundamentalmente interdisciplinares, seus conceitos entrelaçam-se nas diversas aplicações, o que não significa dizer que uma é decorrente ou derivada da outra.

Primeiramente, a TGS buscou formular princípios válidos para os sistemas em geral, independentemente das entidades que os constituíam. Entende-os como emergências: a totalidade, que não se reduz a uma simples soma de seus constituintes. Trata a realidade de forma holística e total, a TGS concebe o sistema como composto de relações internas, consigo mesmo, e relações externas, com os outros sistemas numa cadeia de sub e supra-sistemas. Os pressupostos apontados por Bertalanffy (1973) fora aplicados nos diversos campos do conhecimento, tais como: embriologia, sistema nervoso, cognição, economia, sociológica, ecologia, geografia etc. Para a perspectiva ambiental, os conceitos de ecossistema, da Ecologia, e geossistema, da Geografia, constituem derivações da influência da TGS, além de constituírem um sólido arcabouço conceitual para os estudos e modelos ambientais em geral.

A Cibernética foi definida por N. Wiener como "a ciência do controle e da comunicação no animal e na máquina” concebida como a “Teoria das Máquinas”. Aqui o termo máquina é empregado no sentido de funcionamento, e não em relação à natureza, ou materialidade, de seus constituintes. Esta ciência não questiona, portanto, o que é? esta máquina, mas, sim, quais são seus aspectos funcionais - o que esta faz ou pode fazer? (ASHBY, 1970, p. 1). A constituição desta disciplina teve por objetivo encontrar princípios de funcionamento nos seres vivos que pudessem ser reproduzidos nas máquinas artificiais, com vista a desenvolver mecanismos artificiais com comportamentos cada vez mais automáticos.

Utilizou-se como modelo básico de máquina de conhecer (seres vivos) uma calculadora aritmética denominada máquina de Turing. O funcionamento desta máquina permitiu essenciais observações sobre o dinamismo do conhecer. Apesar de suas produções serem geradas por cálculos e computações mecânicas em linguagem binária (0 e 1) numa fita, o seu funcionamento global não pode ser assim caracterizado. Está aí se referindo às características globais, ou emergenciais, que o todo adquire, pois acabou ficando constatado que a dinâmica do funcionamento gerado no conjunto apresentou-se em domínio, ou em uma esfera de ação, distinta do das tabulações mecânicas de dados. Assim, concebe-se que o entendimento do seu comportamento, como resultado emergente, está além das descrições mecânicas, o que aliás constitui uma das bases formais matemáticas para o entendimento do conhecer (DUPUY, 1996, p.34).

O desenvolvimento do conceito de retroalimentação (feedback), foi de fundamental importância para o projeto cibernético, possibilitando a partir dele importantes derivações conceituais. Trata-se do processo de informação que permite à máquina, ou ao ser vivo, regular o seu comportamento em função dos resultados obtidos a partir de seu próprio funcionamento, também chamado retroação (ASHBY, 1970, p.62). Distinguem-se basicamente dois tipos de retroalimentação, os feedbacks negativos, responsável pelos efeitos corretivos, e o feedbacks positivos, ligado à desintegração e transformação do sistema. A relação funcional de equilíbrio dinâmico trazida pela retroação conduziu à formulação de conceitos como os da organização e estrutura, empregados sumariamentes como o conjunto de relações de condicionalidade, adaptabilidade, dependência, agrupamento e funções que distingue um sistema como classe singular (organização), e conjunto articulado dos componentes e das relações que constituem o sistema e configuram a sua organização (estrutura) (ESTEVES DE VASCONCELLOS, 2001, p.219).

A cibernética enriqueceu-se com o desenvolvimento paralelo das teorias da informação, comunicação a partir das correlações realizadas por cientistas como H. V. Foerster e J. V. Neumann. Estes relataram que, diferentemente das máquinas artificiais, as máquinas vivas possuíam a capacidade de auto-reformarem os seus próprios constituintes, que se degradavam durante a sua dinâmica funcional. H. V. Foerster percebeu que em determinados sistemas abertos, que detinham desequilíbrio termodinâmico, os feedbacks positivos, responsáveis pelo aumento do desvio ou desajuste no sistema, não somente os levariam à destruição ou desintegração, mas poderia ser também responsável por fonte de ordem e complexização no sistema, nutrindo sua organização, regulação e manutenção, não apenas por meio dos feedbacks negativos, mas também dos gastos, perturbações e ruídos provindos do ambiente. Essa capacidade distingue os sistemas morfostáticos, que funcionam sob mecanismos retroativos mais simples, como um carro, dos morfogenéticos, que possuem uma redundância 
que possibilita ao sistema evoluir ao alimentar-se da ordem e desordem provinda do ambiente, como são os seres vivos. Esses últimos caracterizam-se por uma dinâmica espontânea auto-ordenativa ocorrida a partir do seu próprio funcionamento. A singularidade desse processo foi um dos principais fundamentos para a formulação do princípio da "ordem a partir do ruído" de Von Foerster, e do que depois seria denominado de auto-organização.

Na ciência clássica, a noção de ordem preponderava e dissolvia a idéia de ruído e desordem nas descrições físicas, não atribuindo-lhes significância. A máquina do mundo newtoniana, por exemplo, considerando o Universo regido por leis deterministas, permitindo conceber o Universo como estável e equilibrado, com as desordens e instabilidades apenas aparentes e momentâneas, desmascaradas e dissolvidas pelo método científico na ordem matriz préconcebida (MORIN, 2000, p.199). A partir da segunda metade do século XX, com o desenvolver científico, as desordens, instabilidades e desequilíbrios, presentes já na termodinâmica e em outros ramos da física, que já concebiam a idéia de não-determinação, adquirem, com a constituição da física do não-equilíbrio e dos chamados sistemas dinâmicos complexos, estatuto de significância descritiva.

Inicialmente no campo da metereologia, foi observado que pequenas diferenças na entrada de um simulador atmosférico poderiam gerar, com o decorrer do tempo, significativos desvios de sua trajetória. Essa situação encontrou concordância com desenvolvimentos da física do nãoequilíbrio e da teoria dos sistemas dinâmicos (LUZZI; VASCONCELLOS, 1999, p. 2), com as pequenas flutuações, ou ruídos, ganhando realce na descrição dos sistemas dinâmicos nas diversas escalas, associados às fontes de bifurcações e inconstância evolutiva do sistema, denominando de "sensibilidade às condições iniciais". As constantes e infinitas interações que um sistema dinâmico realiza com o seu ambiente, apesar de sensível às condições iniciais, não o tornam dependentes, ou determinados por ela, pois possuem a liberdade, também descrita como não-integralidade, e relativa imprevisibilidade de evolução. Essas condições são alguns dos ensinamentos trazidos pela Ciência do Caos, no qual o "efeito borboleta" é uma de suas proposições mais conhecidas.

No campo dos sistemas termodinâmicos longe-doequilíbrio observou-se que as instabilidades, ou flutuações, produtoras de entropia no sistema, constituíam, não apenas um processo de degradação irreversível, mas, também condição para dinâmicas construtivas. Ficara constatado que sob determinadas condições de desequilíbrio termodinâmico a matéria poderia adquirir propriedades criativas e organizacionais, e, caso envolvesse um significativo número de componentes individuais estruturados, interagindo e co-existindo entre si, poderiam surgir espontaneamente comportamentos coerentes em nível macroscópico, como é o caso dos átomos, vida, sociedades, estrelas etc, modelo denominado de estruturas dissipativas (PRIGOGINE, 1996). A não-linearidade das interações, e as conseqüentes flutuações, constituiriam as procedências das bifurcações e transições de comportamento vivenciadas pelo sistema em sua evolução (PESSOA JUNIOR, 2006, p. 44).

A consideração da irreversibilidade e das instabilidades é essencial para a compreensão destas estruturas, pois estas propriedades caracterizam as potencialidades criativas e de transformação do sistema. A noção de irreversibilidade desempenha, associada à dinâmica dos sistemas instáveis e caóticos, a idéia de descrição evolucionista, no sentido de constituir um fluxo unidirecional e irreversível ligado à produção de entropia, denominado Flecha do Tempo. As pequenas mudanças nas condições iniciais ocasionadas pelas flutuações e instabilidades, e que constituem as bifurcações originárias dos desvios, podem ser amplificadas, fazendo com que, no decorrer do tempo, o sistema perca a memória de suas condições iniciais. Essa propriedade de não-integralidade, comum aos sistemas dinâmicos complexos afirma a não possibilidade de reversão da evolução temporal do Universo, mesmo que seja teoricamente. De forma inversa, também não é possível uma previsão objetiva do futuro, estabelecido apenas em termos de cenários probabilísticos associados a uma rede complexa de causalidades, corroborando a idéia de que o futuro está sempre em vias de criação.

A redundância ao contrário das incertezas, perturbações é a responsável pela manutenção da ordem no sistema, e que, mesmo detendo instabilidades, ainda conservam o caráter seu determinístico de manutenção; porém, esta é sempre nutrida pela indeterminação, que detém uma relação de concorrências, antagonismos e complementaridades que permitem manter o dinamismo de sua organização em estado criativo (caos determinístico). O criativo, nesta perspectiva, pode ser considerado como a produção do novo, resultado de um processo de transformação organizacional, caracterizando-se pela formação de estruturas novas e funcionamentos novos, evidenciando que 
a criação é uma emergência do sistema (D’OTTAVIANO; BRESCIANI FILHO, 2004, p. 19).

Algumas destas estruturas podem apresentar no nível dos seus elementos uma cooperação auto-referente de dinâmicas. Observa-se o estabelecimento de uma coerência global no sistema, com transferências de níveis locais para os globais. Essa situação, já presenciada na cibernética (morfogenia), fora considerada por Prigogine como o princípio da "ordem a partir das flutuações", e que, em conjunto com a "ordem a partir do ruído", de V. Foerster, e o "acaso organizador", do biólogo H. Atlan, constituem estes os principais fundamentos para a emergência na ciência do chamado princípio da "desordem criadora”, tendo como conceito chave o da auto-organização.

A idéia de auto-organização derivou-se, assim, a partir do reconhecimento das instabilidades, flutuações, ruídos como fontes de ordenação e complexificação na evolução dos sistemas dinâmicos. Portanto, só pode haver auto-organização em sistemas que funcionam longe-do-equilíbrio, ou seja, em regime de trocas de energia, matéria e informação provindas do ambiente, fontes de sua manutenção organizacional. O prefixo "auto", nesta perspectiva, corresponde à idéia de referência a si mesmo, havendo autoorganização toda vez que ocorrer a reestruturação de uma forma ao longo de um processo, no qual a reestruturação se deverá principalmente pelo dinamismo do próprio processo, e somente em grau menor às suas condições de partida e intercâmbios com o ambiente (LUZZI; VASCONCELLOS, 1999, p. 19, DEBRUN, 1996, p. 4).

As considerações destas noções proporcionam uma visão abrangente que embasa lógico-formalmente dinâmicas que contemplam desde processos físico-químicos, ecológicos e climáticos, até humanos, culturais, comportamentais, sócio-econômicos, adminstrativos etc. Subjazem, por isso, controvérsias históricas como, por exemplo, a dicotomia entre mecanicismo e vitalismo nas ciências biológicas que pode, neste caso, ser associado à dualidade sujeito/objeto ou homem (sociedade)/natureza, sem que, para isso, o humano seja desqualificado pela perspectiva física (PRIGOGINE, 1996, p. 157-167, LUZZI; VASCONCELLOS, 1999, p. 93, MORIN, 2002).

Quando os sistemas vivos são explicitados, entra-se em outro domínio de auto-organização, que na perspectiva biológica cibernética denomina-se autopoiese. Nesta, não é apenas considerada a idéia de processo, mas também a de projeto, no sentido de ser algo, inerente ao programa genético dos constituintes biológicos. Os seres vivos são as únicas máquinas (estruturas dissipativas) na natureza que produzem a si próprios, a partir de uma rede de produção na qual os seus componentes criam o sistema circular que os produz, numa relação de congruências próprias e de uma relação de autonomia e dependência para com o ambiente. A dinâmica existencial do ser vivo dá-se, portanto, em multidomínios, ou esferas de ações distintas, que mantêm uma relação de geratividade mútua, mas que não são entendíveis pelos mesmos termos (máquina de Turing): interno/fisiológico e externo/conduta (MATURANA; VARELA, 2001, p. 87).

Em determinadas espécies, as condutas, ou comportamentos entre os seus indivíduos, podem gerar a emergência do fenômeno social. Concebe-se aí uma rede de interações formada entre as unidades, constituindo um novo espaço autopoiético de existência, considerado de terceira ordem. Nesta situação, as unidades ficam subordinadas à manutenção da autopoiese de ordem superior, que, por sua vez, ganha singularidade pela dinâmica singular provinda dos seus constituintes. Por ser composto por seres vivos, todos e cada um constituem o seu operar, não existindo, assim, componentes supérfluos num sistema social; com isso, as alterações que ocorrem no nível dos indivíduos, afetam de forma inevitável o sistema social que este constitui e gera.

No que se refere ao homo sapiens, a sua alta capacidade cerebral cognitiva potencializa-o à humanidade, porém esta é somente estabelecida na relação com outros da sua espécie. Sua desenvoltura social a partir da linguagem como mecanismo de interação, capacita e potencializa a produção e a reprodução da cultura, meio pelo qual o sapiens realiza-se como humano ao produzir e reproduzila. Nestes termos, não é contraditório dizer que a individualidade humana é social, com a biologia potencializando, mas não produzindo a cultura, esta constituída apenas no relacionamento social dos indivíduos. A conduta de uma sociedade fica, assim, subordinada às mudanças de conduta de seus membros, pois ao realizar-se como indivíduo, o homem constitui, compõe e integra o ambiente social em que vive.

\section{Aspectos da relação homem/natureza (sujeito/ objeto)}

As considerações teóricas deste contexto contemplam ensinamentos e ferramentas para diversos campos. 
Direcionado aos estudos ambientais, conferiu-se aqui maior ênfase às considerações relacionadas à inerência do Humano à Natureza, com vista a concebê-los sob um mesmo foro, porém realçando suas singularidades de manifestação e entendimento.

A interconexão dos corpos observada no nível quântico revela a arbitrariedade da noção de separação ou fragmentação física, nada existindo de isolado no Universo. Em conseqüência, os princípios como o da incerteza e o da complementaridade conduzem a que esta nãoseparabilidade resulte numa incontornável situação de interferência estrutural do sujeito no objeto estudado questiona a dualidade ontológica do sujeito(espírito)/ objeto(matéria), uma vez que, fica estabelecido um continuum entre a vontade (método) do sujeito e a propriedade do objeto (onda/corpúsculo).

As descrições da realidade passam a se manifestar apenas por meio de aproximações, rompendo ao mesmo tempo com a idéia de determinação, previsibilidade e objetividade científica. Essas considerações físicas arrefecem o anseio científico de um conhecimento objetivo da realidade, com a ciência se tratando sempre de respostas obtidas pela aplicação de métodos, ou, perguntas feitas a um objeto a partir de certos pontos de vista, sendo eles sempre de incompletos, realçando o fenômeno, no sentido, de aparição à consciência, na física. Pode-se dizer, então, que as distinções e contradições presenciadas no nível fundamental da matéria (onda/corpúsculo, energia/matéria) e na relação sujeito e objeto do conhecimento, perdem o seu caráter dualístico em favor de um continuum (SANTOS, 1998, p. 26).

Nas teorias sistêmicas, a interconexão dos sub e supra-sistemas vieram realçar as singularidades que constituem as emergências como produto da funcionalidade dos sistemas. Concebida como uma totalidade nas proposições de Bertalanffy (1953), e, já observada no nível experimental da máquina de Turing, na cibernética, as emergências representam o algo de original que surge como expressão de um novo tipo de estado de inter-relações distinto da dos constituintes pré-existentes. Apesar de pertencerem à mesma realidade, os constituintes e as emergências não podem ser concebidos e entendidos pelas mesmas formas e termos, pois se encontram em domínios de ação e comunicação distintos.

A visão sistêmica dos seres vivos, a partir de tais bases, desenvolve assim uma atitude epistemológica intermediária à tendência dual da relação sujeito/objeto. Historicamente, a vida tem sido basicamente tratada pelo co- nhecimento científico a partir de duas perspectivas distintas: o vitalismo, ligado um princípio vital global não redutível e estendível às leis físico-química, e o mecanicismo, materialismo e naturalismo explicando a vida a partir dos princípios mecânicos físico-químicos das leis da matéria. Essa dualidade descritiva pode ser concebida como da mesma natureza da distinção sujeito/objeto, com o sujeito (espírito) ligado ao vitalismo, porém sem o reconhecimento de sua animalidade, e o objeto ligado ao materialismo-mecanicismo, referente ao corpo, ou a realidade física, correspondendo e representando a distância ontológica entre o componente humano (vital global) e a natureza física (materialista). Sem distinguir os tipos de animais, na perspectiva sistêmico-cibernética, os domínios de existência, apesar de distintos, são tratados complementarmente - mecanicista em seus aspectos fisiológicos, lidando com máquinas do universo físico fenomenal, e vitalista no nível dos fenômenos comportamentais emergenciais (MATURANA, 1997, p. 108).

A especificidade humana, nesta linha está ligada à produção de conhecimento/cultura por meio da linguagem, mas ela, a cultura, não transcende à animalidade do corpo, que dele emerge no social. O sujeito/objeto é assim concebido de forma relacional, porém com existências disjuntas que não se intersectam, no sentido de que os processos de um não ocorrem no outro. Existe, porém, uma relação de geratividade mútua, cujo domínio da conduta emerge como resultado global da dinâmica fisiológica do organismo, que, por sua vez, o guiará no curso de sua própria mudança estrutural. Assim, apesar de disjuntos, modulam-se recursivamente, de maneira complementar, no viver, com um deles podendo não ser explicável em relação aos termos do outro, somente compreendidos em seus próprios âmbitos.

Nesta perspectiva há também o questionamento da objetividade do conhecimento, em correspondência com as proposições da física quântica, ficando realçado que a noção de realidade é sujeito-dependente. Assim, considerando que as células nervosas desempenham o papel de filtros da realidade, não é possível chegar à conclusão de que existe algum traço de objetividade do mundo exterior a partir da configuração destas células, ou seja, o sujeito não é alheio aos fenômenos que observa e interpreta (MATURANA, 1978, p. 149, FOERSTER, 1978, p. 130). O conhecimento científico é, assim, sempre mediado por representações e significações simplificadas, que podem ser vistas fundamentalmente como modelos, ou represen- 
tações, que não dizem respeito à realidade, mas aos questionamentos que nós, sujeitos vivos-sócio-culturais, fazemos da realidade. O sujeito não é mais apenas o mero conhecedor do objeto, mas também objeto do conhecimento, já que a relação estabelecida entre o sujeito e objeto também se torna objeto de questionamento.

As leis mecânicas da ciência clássica concebidas após Newton prescreviam as descrições dos movimentos dos corpos sem uma orientação definida para o parâmetro Tempo. Centrado na intuição interna do sujeito em Kant, poderia ser arbitrariamente direcionado tanto de maneira positiva, para frente, quanto de maneira negativa, para trás. A idéia de um Tempo simétrico pressupõe a idéia de um Universo ordenado, passível de ser descrito objetivamente e de maneira determinista, tanto no que se refere à evolução futura, quanto à passada. Num universo descrito linearmente, não haveria espaço para o novo, para a criação; neste sentido, ao orientar a evolução num sentido unidirecional irreversível, ligado a uma dinâmica complexa não-linear, as estruturas dissipativas romperiam com a determinação, ao mesmo tempo em que quebrariam a simetria do Tempo (PRIGOGINE, 2002, p. 31-77). Os processos criativos associados à produção irreversível de entropia, a partir das flutuações e instabilidades, demonstram o papel construtivo que pode desempenhar a desordem, ruídos e perturbações, como bem podem ser exemplos, a emergência da vida, os furacões, sociedades, redemoinhos, culturas etc.

Na física, a distinção linearidades/não-linearidades representa uma das manifestações do dualismo do conhecimento ocidental - necessidade-liberdade, determinação/ contingência, física/humano, sujeito/objeto (MORIN, 2001, p. 270). Com o retorno das não-linearidades/contingências/liberdades como inerentes à dinâmica física e descritiva da natureza, ocorre a reabilitação do sujeito na dinâmica do objeto (Natureza), que agora reconhece a consciência, criatividade e liberdade humana naquela linearidade/determinação/causalidade que agora caminha numa evolução dissipativa em comunhão com a criatividade, que é própria da Natureza e do conhecer humano.

Todo sistema físico é, assim, um vir-a-ser dependente do seu ambiente e submetido ao tempo, que não é apenas aquele que vai do nascimento à dispersão, mas também o da evolução, com todos detendo a finitude (entropia) que antes era apenas reservada ao homem. Essas considerações físicas reintegram o sujeito no que Morin (2002, p. 335) denomina physis renovada, ou seja, na Natureza que ele descreve, como ser vivo concebido enquanto máquina cibernética, associado ao universo das estruturas que dissipam energia (PRIGOGINE, 2002). Convém destacar que esta consciência vem do campo das ciências físicas, que na perspectiva sistêmica realça o sujeito sem transcendê-lo à realidade física, mas emergindo-se dela como resultado de uma dinâmica complexa.

Mesmo fornecendo um arcabouço que subjaz e associa os multi-domínios e dimensões da realidade, essas considerações não dissolvem os antagonismos e as contradições presentes, principalmente no que tange à relação homem e a natureza. Realça-se, ao contrário, a impossibilidade e a inadequação de se eliminarem suas diferenças e singularidades de manifestação e entendimento. Aplicados e interpretados por sujeitos não alheios, o caráter descritivo da ciência ressalta a limitação de representação e a unilateralidade das respostas obtidas pelos métodos de questionamento. A exemplo dos conhecimentos da física atômica, esses ensinamentos podem sugerir confrontos e somas complementares de perguntas e respostas a partir de métodos paralelos como forma de se obter um mais abrangente e adequado conhecimento multidimensional da realidade. Neste sentido, o esforço pode ser para a constituição de caminhos estratégicos que detenham consistência teórico-metodológica necessária para a promoção de abordagens flexíveis consistentes, pautadas em devidas conciliações que finalmente possam ser revertidas em modelos práticos abertos à articulação sugerida.

\section{As aproximações com os estudos e modelos ambientais}

Apesar de nem sempre se tornar explícita, a abordagem sistêmica encontra-se presente na maioria das aplicações dos estudos ambientais. Por vezes, de caráter implícito, esta pode ser vista em estudos que relevam as inter-relações dos fatores que compõem o meio como forma de entendimento da dinâmica física ambiental (GOMES; ESPINDOLA, 2006, p. 588-593). As adequações teóricas do contexto sistêmico encontram-se em conceitos operacionais como o ecossistema de Tansley, o geossistema de Sotchava, e em metodologias práticas que se apóiam no sistema como suporte conceitual para o tratamento integrado dos componentes ambientais e interferências humanas.

Por estarem diretamente ligados à complexidade física da natureza, muitas das aproximações conceituais e analíticas em relação aos avanços descritos estão vincula- 
das aos estudos da dinâmica dos sistemas físicos ambientais. O conceito de entropia, por exemplo, como significação e parâmetro de expressão dinâmica, faz reconhecer que a rapidez de consumo dos recursos naturais e energéticos disponíveis no mundo diminui o tempo e as condições dos que permanecem à disposição de nossa sobrevivência e gerações futuras, além de oferecer embasamento formal com inúmeras aplicações práticas (TIEZZI, 1988, p. 32). Entretanto, assim como a auto-organização, ou o caos determinístico etc estes fenômenos são, muitas vezes, mais fáceis de serem conceituados do que experienciados empiricamente. Por isso, mesmo já oferecendo relevantes associações teóricas, pode se dizer que para os estudos ambientais as aproximações com os sistemas complexos ainda estão fase de reconhecimento e organização.

O caráter implícito com que as teorias são tratadas em estudos e modelos ambientais acaba dificultando sua reflexão teórico-epistemológica em favor de procedimentos práticos mais normativos e unilaterais. Embora detenham consistências e reconhecidas eficiências, as descrições analíticas acabam ficando limitadas frente as multilateralidades e contingências dos problemas e desafios atuais. Para isso, os aspectos teóricos, norteadores dos procedimentos práticos, precisam ser aprimorados para a conciliação e ampliação de bases. O avanço e refino do conhecimento sistêmico podem oferecer interessantes considerações acerca desta necessidade, porém a amplitude do contexto exige que as aproximações sejam encaradas de forma apropriada. As aproximações estão, em sua maior parte, associadas a aprimoramentos descritivos formais e empíricos que enquadram a dinâmica destes sistemas no contexto dos sistemas complexos.

Inicialmente, os modelos de predição que utilizam ferramentas estatísticas procuram reconhecer os padrões précaóticos presentes na dinâmica dos constituintes espaciais como forma de decifrar a incerteza determinística pelos quais os processos estão sujeitos (CULLING, 1987, p. 66-67, PHILLIPS, 1994, p. 391). Essas ferramentas podem ajudar na descrição de padrões rítmicos presentes nos processos que se alternam ao longo do tempo e que refletem o caoticidade do processo, pelas suas susceptibilidades às diferentes condições iniciais e seus potenciais desencadeamentos. A evolução da maioria dos sistemas complexos ambientais traz, inerente a si, sensibilidade a pequenas flutuações e, considerando as nuanças envolvidas na trama dos infinitos fatores ambientais podem ser constituídos facilmente instabilidades contingentes na funcionalidade do sistema, o que o torna evolutivamente incerto.

As condições caóticas presentes nos sistemas ambientais exibem ordens com padrões complexos em diferentes escalas e com limites definíveis, mesmo que arbitrariamente. As ordens em pequenas escalas podem surgir do caos das grandes escalas, produto das regras e regularidades que proporcionam as emergências a partir de uma complexidade subjacente (PHILLIPS, 1994 apud CHRISTOFOLETTI, 1998, p. 68). A estabilidade adquirida refere-se ao equilíbrio dinâmico estabelecido na congruência de estados nas diferentes e variadas escalas, que, por sua vez, variam do nível individual ao conjunto, podem ser entendidos como a própria capacidade que um sistema tem de manter sua organização geral. Assim, mesmo que haja alterações nas condições de fluxo no nível dos componentes, não necessariamente essa flutuação irá influenciar o nível do conjunto, em escalas menores, podendo ser absorvido por esta estabilidade subjacente (MATOS, 2003, p. 2572).

Os componentes que representam o quadro ambiental, tais como clima, solo, hidrografia, geologia, vegetação e ação humana, por serem constituintes típicos, encontram na teoria dos sistemas dissipativos um modelo invariante que unifica suas dimensões e domínios rítmicos num integrado e multi fluxo sistema de matéria e energia. Apresentam, assim, tanto aspectos universais, de caráter determinístico, quanto aspectos caóticos, descritos por probabilidades, e que representam os aspectos históricos que formam os acasos imprevisíveis. Seus ritmos são reconhecidos pelas características estruturais e morfológicas dos componentes, conjunto e processos envolvidos (HUGGETT, 1988, p. 45-49). Em contexto aos tratamentos estatísticos matemáticos e empíricos, a concepção de Tempo trazida por esta noção de estrutura, integra os fenômenos criativos, de forma que, os sistemas ambientais dissipativos podem ser considerados como a matriz pela qual o homem emergiu, atribuindo significados e produzindo, por meio de sua conduta físico-sócio-cultural, o espaço geográfico que ele descreve.

A auto-organização também pode ser reconhecida na dinâmica dissipativa dos sistemas ambientais, dependendo da escala espaço-temporal adotada. Nesta dinâmica, a interconexão dos fatores físicos ambientais pode apresentar em sua evolução, conjuntamente fases e processos dissipativos que são auto-organizativos e que não são autoorganizados (PHILLIPS, 1995, p. 309-321). Há auto-organização quando aspectos superficiais de um determinado 
componente, ou (sub)sistemas, se organizam em padrões ordenados ou repetitivos na relação de um com os outros, devido aos próprios processos internos gerados no sistema, independentemente dos seus controles externos. No entanto, Phillips (1995, p. 318) adianta que a auto-organização se aplica a diferentes fases e estágios de evolução da paisagem, não sendo, porém, uma característica inerente a seus componentes, sendo mais conveniente dizer que a evolução destes pode estar se auto-organizando, do que, realmente são auto-organizados.

A visualização e definição empírica na paisagem, de fenômenos caracterizados como sistemas complexos ainda estão em fase de reconhecimento; com isso, também são carentes suas adequações teórico-conceituais, que são os norteadores dessas visualizações, entendimentos e execuções. Sem isso, as conversões de caráter metodológico e prático correm o risco de não ganharem uma operacionalidade definida, restringidas pelo déficit teórico. Nessa situação, as barreiras não transpostas inviabilizam a realização de contextualizações adequadas nos modelos integrados, não conseguindo contemplar a complexidade e oferecer operacionalidade viável e eficiente às correspondências e reciprocidades dos sistemas humanos, ecológicos, geográficos etc.

Como visto, os modelos de estudo ambientais, mesmo que de forma implícita, carregam a perspectiva dual que a pressuposição de um tempo reversível traz. Assim, mesmo que a noção de entropia, que direciona o tempo irreversível, não seja novidade para os estudos sistêmicos geográficos (Cf. CHORLEY; KENNEDY, 1971, p. 13), isso, não impede que fundamentos e interpretações clássicas associadas ao tempo reversível ainda estejam influenciando os aspectos analíticos e operacionais nos modelos. Para a Teoria dos Sistemas, por exemplo, essa influência causa, mesmo que de uma forma relativa, a homogeneização artificial da dimensão temporal. Para os modelos ambientais isso reflete na consideração de condições espaço/temporais momentâneas no sistema considerado, sem, por vezes, dar a devida atenção às interconexões e influências recíprocas causadas pelas dimensões e domínios genéticos e evolutivos que estão presentes em outras escalas (SCHUM; LICTHY, 2004 apud SALES, 2004, p. 129).

O fluxo entrópico que permeia os sistemas dinâmicos não-lineares e a sua interconectividade do nível micro (átomo) ao macro (galáxias etc), referentes à idéia de uma Flecha do Tempo (PRIGOGINE, 1996), revela as multitemporalidades e reciprocidades dos ritmos da Natureza, independentemente dos dualismos entre os domínios e dimensões (humano, físico, local/individual, global/coletivo). A noção de ritmo, já explorada em estudos ambientais, por exemplo, em Monteiro, (1991), continua sendo referência para avaliação de suas potencialidades descritivas do comportamento e evolução dos sistemas espaciais e ambientais. Sob este foro rítmico, pode-se conceber que os desequilíbrios, desordens, bifurcações e flutuações, antes associados apenas às influências antrópicas no “equilíbrio" dos sistemas ambientais, pode agora ser concebido como próprio e inerente à dinâmica evolutiva (criativa) da Natureza, com suas singularidades e complexidades de manifestação e entendimento.

Conceber o homem (sujeito do conhecimento) como inerente à dinâmica física da natureza, acaba por reafirmar a não existência objetiva de qualquer representação modelo-conceitual feita do quadro homem/natureza. As delimitações e discernimentos obtidos a partir das organizações espaciais resultantes são, nesta perspectiva, referentes aos arbítrios do pesquisador, tornando-se responsável intelectual pelo refinamento e aplicação dos modelos-conceituais. As definições e limites ficam, assim, dependentes de sua experiência e dos objetivos da pesquisa, com os parâmetros e variáveis sendo relevadas em meio à infinita e intricada “artificialidade” dos objetos e intervenções humanas nos sistemas ambientais.

Muitos fenômenos humanos, como o social, o econômico, o administrativo, o urbano e outros, detêm aspectos de suas dinâmicas como típicas e, por isso, podem ser concebidos e descritos de forma analítica sistemicamente. No entanto, para os estudos ambientais, isso não sugere um modelo global de entendimento, pois, como visto, ficou revelada que as emergências, principalmente para os seres vivos (cibernética-máquina de Turing), encontramse em domínios distintos das dos componentes, com singularidades e especificidades que, muitas vezes, não permitem ser descritas, pelo menos de uma forma mais adequada, pela análise sistêmica. Com isso, a melhor compreensão das singularidades dos domínios emergidos, fica dependente do esclarecimento de aberturas que permitam a utilização e articulação de diferentes conhecimentos como forma mais adequada para o tratamento da singularidade de manifestação de domínios e dimensões estudadas.

Na perspectiva de um tratamento ambiental mais adequado da conjunção humano/físico, acredita-se pertinente relevar as considerações de Morin (1999, p. 87-109), para quem, discorrendo sobre a complexa relação humano/ma- 
téria, cérebro/espírito, acredita ser primeiramente necessário lembrar que a identidade comum entre eles, humano e físico, ainda não fora identificada, e, depois, de que comportam uma contradição insuperável, pois se trata da identidade do não idêntico. Presente no próprio fundamento de um conhecimento possível (HESSEN, 1968, p. 26), essa dicotomia histórica requer a precaução contra possíveis misturas infundadas de conteúdos sem os devidos esclarecimentos teórico-metodológicos para nortearem as comunicações. Nestas, além de se correr o risco da efemeridade dos contatos, os modelos resultantes podem acabar por dissolver importantes singularidades de manifestação, muitas vezes relevantes para o entendimento e ação de alguma realidade.

De uma forma geral, nos diagnósticos ambientais sistêmicos a síntese do meio antrópico advém da quantiqualificação das informações colhidas. As espacializações, em mapas temáticos, muitas vezes vêm acompanhadas de textos anexados que detalham as nuanças que ainda não são bem representadas em cartas (costumes culturais, valores, percepções etc). São tratados, por exemplo, aspectos demográficos (crescimento, densidade etc), infra-estruturais urbano, fundiário, produtivo (saneamento, habitação, abastecimento, emprego etc) e costumes culturais, percepções ambientais, atividades econômicas formais e informais, renda, classe social, hábitos alimentares, grau de escolaridade, disponibilidade e acesso à sistemas de saúde, educação etc. Bem colhidas, essas informações já oferecem significativo contexto para trabalhos de diagnósticos, porém, conforme visto, as limitações analíticas frente ao fenômeno emergencial-humano podem exigir perguntas mais adequadas à especificidade de certas nuanças, podendo requerer a utilização de outros procedimentos e abordagens para a complementação das informações humanas colhidas.

Neste panorama, pode se dizer que os mitos das eficiências técnicas e da utilização unilateral de métodos racionais de decisão já vêm sendo questionados em favor de diagnósticos e planejamentos mais participativos nos seus aspectos sócio-econômicos e culturais. Procuram abordar as contradições geradas na relação sociedade com os sistemas físicos naturais por meio de novas posturas frente aos problemas a serem enfrentados (ALMEIDA et al., 2002, p. 39). Essa racionalidade técnica favorece, nos estudos de planejamento a atuação em sistemas urbanos e agrícolas atrelados à idéia de um desenvolvimento industrial, econômico e político. Porém, pouca atenção tem sido dada às necessidades psicológicas e emocionais do viver urbano e rural, deixando de relevar aspectos fundamentais para a valorização do Humano, como são a qualidade de vida, os anseios dos indivíduos e as oportunidades que os ambientes oferecem nas diferentes sociedades. Mas considerando o caráter cultural da crise ambiental, pode se dizer que esse favorecimento técnico acaba por não abordar adequadamente aspectos primordiais dos problemas contemporâneos, compondo ainda um vasto campo a ser explorado (BALDWIN, 1985, p. 277).

O problema de se tratar o físico-natural e o humano conjuntamente é um questionamento constante nos estudos ambientais, por isso considerações pertinentes já foram levantadas para melhor pensar e operacionalizar, de uma forma mais flexível, o tratamento dessas esferas. Se basear, por exemplo, numa perspectiva ecológica, é possível conceber dois tipos de estudo não excludentes das interações do homem com o ambiente natural. Inicialmente pode-se tratar o homo sapiens, pela sua condição biológica, como emergente dos sistemas naturais e pertencente ao seu ambiente físico e, com isso, com certas imposições e limites. As influências recíprocas com o ambiente são assim condições essenciais para a manutenção das necessidades humanas, enquadrando-se nos estudos da ecologia humana. Os ensinamentos cibernéticos (Turing, autopoiese) podem ser correlacionados, nesta abordagem, pela distinção observada e descrita entre as esferas físicas e emergenciais da conduta e do social, que, no caso do homo sapiens, potencializa o seu desenvolver cultural. Neste outro domínio que é a cultura, recorre-se à ecologia cultural, referindo-se ao dinamismo do ecossistema humano, diferenciado da dos outros animais pela sua maior capacidade de produção e reprodução de cultura. A linguagem humana potencializa esse processo e, pela acumulação dos ensinamentos e tradições herdadas pela escrita impressa, favorecem-se e acentuam-se os refinamentos de princípios, teorias, interpretações, ferramentas, técnicas etc (KOLARS; NYSTUEN, 1975, p. 252).

Para o entendimento da dimensão cultural, fica assim, realçada a necessidade de estudos que forneçam, além dos índices analíticos sócio-econômicos e infra-estruturais, também cenários obtidos a partir do contato com a própria comunidade, colhendo aspectos de suas experiências, percepções, vivências e perspectivas. Para a sua realização, os métodos e ensinamentos ligados a outras perspectivas de estudos ambientais já são conhecidas e constituem abordagens mais direcionadas para estes temas. Este é o caso, por 
exemplo, da noção de Topofilia (Tuan), que, ligado ao campo da fenomenologia, revela aspectos da relação afetiva que o indivíduo e grupo têm para com o ambiente experienciado. Entre o indivíduo e a sua percepção de mundo existem processos interativos dos mais complexos, não passíveis de serem representados por modelos físicos analíticos a partir de uma relação causal de estímulo-resposta. Nas percepções do ambiente, como as de paisagens, convergem aspectos estéticos, táteis, olfativos, sonoros, acompanhados de determinantes psicológicos inatos e sócio-culturalmente adquiridos, compondo o arcabouço ideológico das interpretações individuais. As respostas dos moradores podem oferecer, neste sentido, complemento aos contextos sócio-infra-estruturais levantados, inserindo informações acerca de: situação e qualidade de vida dos moradores, percepção de riscos, vulnerabilidades, consciência ecológica, dificuldades vividas, anseios, perspectivas, além dos panoramas dos valores sociais, culturais, ambientais, econômicos e políticos que orientam suas ações no espaço (OLIVER, 1977, p. 270).

Pesquisadores que utilizam o Geossistema como conceito operacional em estudos integrados do meio ambiente, concebendo-o como um sistema singular complexo, direcionam suas bases conceituais e encadeamentos analíticos para o tratamento a partir do confronto de modelos paralelos - o natural e o social. A modelização baseia-se numa unidade (não uniformidade) teórico-metodológica que aprecia o homem como "derivado" do dinamismo de massas, energia e informação da Natureza. O humano, emergente no social, com suas dinâmicas culturais e econômicas, não são considerados conceitualmente antagônicos e oponentes, mas, sim, incluídos todos no funcionamento do próprio sistema. Tratar de forma distinta e conjunta estes modelos (físico-natural e sócio-econômico) não sugere, nesta perspectiva, um antagonismo de análise, mas, ao contrário, visa dar flexibilidade de articulação para um melhor entrosamento de informações, aumentando a confiabilidade das informações das áreas pelos complementos mútuos de dados (MONTEIRO, 1978, p. 61, MONTEIRO, 2001, p. 53-56, PENTEADO ORELLANA, 1985, p. 131). As dificuldades associadas a esse tratamento exigem que estas pesquisas sejam norteadas não somente pela consciência da necessidade de trabalhos em equipes e pelo esforço de abertura e aceitação por entre os pesquisadores. São necessários também, os esclarecimentos teóricos que promovam as aberturas para outras perspectivas de estudo, embasando as conciliações como forma de promoverem encaminhamentos que ofereçam resultados mais harmônicos no estudo da relação sociedade / natureza.

Assim, a elaboração e a aplicação de abordagens integradas que combinem o desenvolvimento sócio-econômico e a manutenção das potencialidades ambientais torna-se um amplo desafio à sociedade moderna. Uma das tarefas, neste sentido, é a de estruturar uma concepção em que a conservação dos recursos naturais não necessariamente contradiga as metas de desenvolvimento e das necessidades humanas (CHRISTOFOLETTI, 1999, p. 157). Para isso, os modelos de desenvolvimentos ligados à questão ambiental direcionam os esforços para uma maior democratização do processo de estudo e execução, o que realça a necessidade de uma boa representatividade do contexto humano em diagnósticos de áreas.

Relevando que todos e cada um compõem e dinamizam o ambiente social que integra e vive, esse caminho, além de favorecer negociações nas comunidades, entre agentes, segmentos sociais, público e privado, no sentido de garantir os direitos e deveres de atitude de cada setor, incentiva mudanças na postura sócio-cultural dos cidadãos, estimulando sua responsabilidade para com o ambiente mediante participação e acesso às discussões e tomadas de decisão. Os comitês de bacias hidrográficas, no Estado de São Paulo, têm avançado em suas conquistas, mediante o “diagnóstico participativo" em sua metodologia de ação (COLODRO et al., 2000, p. 105). Tal direcionamento mostra-se como uma alternativa para a onipotência da racionalidade técnica, que já não oferece mais respostas tão bem adequadas às necessidades presentes e desafios futuros, exigindo, muito mais, o esforço para cruzamentos consistentes e conciliatórios de conhecimentos e perspectivas.

\section{Considerações finais}

O século XX representou um período de importantes rupturas em relação às bases do conhecimento constituídos da Renascença ao Iluminismo, e, vivido de maneira hegemônica até o final do século XIX. Apresentou um rico contexto de avanços como a relatividade, teoria quântica, refinamentos lógicos e matemáticos, teorias sistêmicas, a física do não-equilíbrio, sistemas dinâmicos, teoria do caos, estruturas dissipativas, teoria da autopoiese etc. Estes representam alguns dos exemplos de significantes teorias que 
trouxeram novos entendimentos acerca das bases constitutivas primordiais da ciência moderna.

Retomando o caráter introdutório deste artigo, neste século, a "teoria" ficou reconhecida como mediadora e direcionadora dos entendimentos acerca da realidade (LAKATOS; MUSGRAVE, 1979), que, pela aplicação do método hipotético-dedutivo (Popper) guiam a formulação das hipóteses e dos modelos práticos operacionais. Com isso a riqueza e poder de representação e intervenção dos modelos ficam dependentes de que haja constantes reajustes teóricos advindos das ciências correlatas, e que, no caso da Geografia, ciência do espaço da superfície da terra, carrega a riqueza e angústia de poder contar com grande parte das ciências enquanto possibilidades de contato. As teorias sistêmicas constituídas na década de 40 e 50 são algumas das quais fortemente influenciaram a ciência em geral e os modelos de estudos ambientais a partir da década de 60. Contudo, a ênfase dada a operacionalidade acabou ofuscando e minimizando as discussões teóricas que deveriam permanentemente alimentar e enriquecer o poder de representação e intervenção dos modelos. Os reajustes em relação às avanços científicos acabam, por isso, tornando-se lentos e isolados, com o perigo dos modelos entrarem em estagnação e não mais oferecerem respostas pertinentes aos desafios da sociedade.

Contra essa tendência reviveu-se alguns dos desenvolvimentos teóricos e experimentais ocorridos ao longo do século XX que permitem questionar e ampliar o entendimento de princípios, ou paradigmas, primordiais do conhecimento científico em geral. Inserido dentro de uma perspectiva sistêmica, buscou-se demonstrar a inerente conexão dos entendimentos ambientais neste contexto, dando maior ênfase em aspectos ligados à dinâmica física da matéria e dualidade sujeito/objeto, demonstrando que estes entendimentos são alguns dos que embasam a possibilidade de um conhecimento mais interdisciplinar entre a primordial dualidade do conhecimento: sujeito/objeto, Homem/natureza, Humanidade/Ciências.

O princípio da ordem universal foi sendo questionado em favor de um balanço com a desordem, tanto em nível energético, quanto no nível descritivo e ontológico do objeto com as: termodinâmica, física quântica, cibernética, teoria do caos, física do não-equilíbrio, estruturas dissipativas etc, compondo e caracterizando o contexto que vem sendo chamado de "acaso organizador". Os balanços entre ordem e desordem, estabilidade e instabilidades, determinismos e indeterminismos, num fluxo energético irreversível e unidirecional do tempo, oferecem no contexto dos sistemas dinâmicos complexos considerações que permitiram conceber a possibilidade da "matéria” se organizar até a formação dos animais superiores e do SujeitoHumano existencial com suas sociedades, culturas, costumes, sentimentos, valores, anseios, fobias, alegrias, tristezas etc. Ao contrário do reducionismo totalitário que isto pode sugerir, estas considerações declaram a não possibilidade de redução das especificidades de manifestação destes fenômenos em relação à dinâmica descritiva física causal.

A dificuldade de efetivação das práticas interdisciplinares, principalmente na relação entre ciências e humanidades, natureza e sociedade podem também ser encontradas na própria raiz cultural da sociedade ocidental, onde o Homem não se observa como parte da Natureza. Entendido como um "ser-máquina" cibernética que se auto-organiza, os seres humanos em conjunto com os outros animais se manifestam em multi-domínios existenciais e descritivos que se modulam e integram no viver, mas que não podem ser reduzidos epistêmico e ontologicamente uns em relação aos outros. Assim, inserido numa physis renovada (MORIN, 2002, p. 335), de forma não contraditória os animais, incluindo o homo sapiens, são, dentro da perspectiva relacional sistêmica, ao mesmo tempo sujeito/objeto, mente/matéria, natureza/cultura, individuo/social, indivíduo/espécie, local/global. A especificidade humana advém da potência da produção de cultura/conhecimento por meio da linguagem, mas estes não "transcendem" a animalidade do corpo, mas emergem dele no social. A objetividade do conhecimento também é abalada pela impossibilidade de se conceber os sujeitospesquisadores do conhecimento como alheios a sua condição espaço-temporal-animal-sócio-cultural. As discussões em torno destes questionamentos acabam reconhecendo aspectos ligados à limitação de representação e a incoerência de se tentar reduzir o real a somente unilateralidades de respostas.

A abordagem sistêmica, focada nas inter-relações, conectadas com entendimentos teóricos e experimentais de avanços científicos parece oferecer amplos entendimentos que já estão sendo aproveitados por pesquisadores, mas que, ainda precisam ser mais bem explorados no Brasil. Além das ferramentas matemático-estatísticas estes entendimentos podem ajudar os pesquisadores a conectarem-se à princípios, já presentes no âmbito científico, que favorecem práticas interdisciplinaridades, com direcionamentos 
estratégicos para condutas científicas mais propícias a aberturas, comunicações e complementaridades entre abordagens distintas.

Apesar de nem sempre presentes de forma explícita, a abordagem sistêmica encontra-se na maioria das elaborações de modelos e das aplicações dos estudos ambientais. Esse caráter implícito dificulta que as reflexões teóricoepistemológicas venham à tona, principal meio pela qual se poderá ampliar de maneira mais segura e adequada às possibilidades dos modelos práticos. As adesões aos avanços nas reflexões experimentais e intelectuais sistêmicas, estão, mesmo que lentamente, sendo conectadas ao dinamismo dos sistemas ambientais por diversos autores, com utilização também para estudos sócio-econômicos-político-culturais.

Devido a esta pouca atenção dada, inclusive às ampliações teórico-epistemológicas das noções apresentadas, tratou-se aqui aspectos teóricos referentes à conjunção entre o físico-natural e o humano. Por ser um dos questionamentos sempre presentes nos estudos geográficos ambientais, muitas considerações pertinentes já foram elaboradas em modelos já conhecidos e utilizados, que já buscavam tratamentos em conjunto mais adequados entre estas duas esferas. Nestas proposições já testadas são concebidas a necessidade de se distinguir entre modelos cultu-

ALMEIDA, J. R. MORAES, F. G.; SOUZA, J. M.; MALHEIROS, T. M. Planejamento ambiental. Rio de Janeiro: Thex, 2002, p.161.

ASHBY, W. R. Introdução à cibernética. São Paulo: Perspectiva, 1970. 345p.

BALDWIN, J. Environmental planning and management. Boulder, Colo.: Westview Press, 1985, 336p.

BERTALANFFY, L. V. Teoria geral dos sistemas. Petrópolis: Vozes, 1973. 351p.

CAPRA, F. O ponto de mutação. São Paulo: Cutrix, 1982. 447p.

CHORLEY R. J.; KENNEDY, B. A. Physical Geography: a systems approach. London: Prentice-Hall International, 1971. 370p.

CHRISTOFOLETTI, A. Perspectivas para el análises de la complejidad y la autoorganización en sistemas geomorfológicos. In: MATTEUCCI, S. D.; BUZAI, G. D. Sis- rais-sócio-econômicos e modelos físico-naturais, como forma de não reduzir as manifestações de entendimento um pelo outro. Ou seja, mesmo vinculados ao veio analítico de entendimentos lógico-causais, modelos já procuram há algum tempo não perderem de vista a descrição de aspectos como culturas, costumes, percepções, atividades econômicas, políticas, escolaridades etc. Entretanto, ainda assim deixam de tratar adequadamente vários destes aspectos, visto exigirem, na verdade, também outras teorias e formas de conhecimento para o seu inquérito.

Ainda em fase de reconhecimento e organização nas disciplinas científicas em geral, procurou-se demonstrar que o contexto sistêmico de avanços do século XX detém pertinentes considerações para a busca de maiores flexibilidades e amplitudes de entendimentos para os modelos aplicados que já vem sendo utilizados. Refere-se à ganhos em refinamentos conceitual-metodológicos e abertura epistemológica para a comunicação com outras teorias e formas de conhecimento. A ciência geográfica, localizada na intersecção da natureza e sociedade, do objeto e sujeito, das ciências e humanidades ganha, em perspectiva, renovadas possibilidades de aberturas inter e intradisciplinares.

\section{Referências}

temas ambientales complejos: herramientas de análisis espacial. Buenos Aires: Centro de Estudos Avançados, Universidade de Buenos Aires, 1998. p. 57-99.

Modelagem de sistemas ambientais. São Paulo: Edgard Blucher, 1999. 236p.

COLODRO, G.; ESPINDOLA, C. R.; SOARES, P. R. B. Participating diagnosis toward social envolving in environmental receiving. In: WORLD CONGRESS OF RURAL SOCIETY, 10.; BRAZILIAN CONGRESS OF RURAL ECONOMY AND SOCIOLOGY, 38., 2000, Rio de Janeiro, p.105.

CULLING, W. E. H. Equifinality: moderns approaches to dynamical systems and their potential for geographical thought. Trans. Inst. Brit. Geogr., London, v. 12, p. 57-72, 1987.

. A new view of the landscape. Trans. Inst. Brit. Geog., 
London, v. 13, p. 345-360, 1988.

DEBRUN, M. A idéia de auto-organização. In: GONZALES, M. E. Q.; PESSOA Jr. Auto-organização. Campinas: [s.n.], 1996, p. 3-23. (Coleção CLE 18).

D’OTTAVIANO, I. M. L.; BRESCIANI, E. Sistêmica, autoorganização e criação. Revista Multiciência, Seção Rede Interdisciplinar, A mente humana, COCEN/Unicamp, v. 3, p. 1-23, 2004.

DUPUY, J. P. Nas origens das ciências cognitivas. São Paulo : Ed. Unesp, 1996. 228p.

ESTEVEZ DE VASCONCELLOS, M. J. Pensamento sistêmico: o novo paradigma da ciência. Campinas: Papirus, 2002. 268p.

FOERSTER, H. V. Teoria da cognição e epistemologia da observação. Observações introdutórias. In: MORIN, E.; PIATTELLI-PALMARINI, M. A unidade do homem. v. 2. São Paulo: Cultrix : ed. USP, 1978, p. 130-131.

GOMES, P. C. C. Geografia e modernidade. Rio de Janeiro: Bertrand Brasil, 2000. 366p.

GOMES, R. D.; ESPINDOLA, C. R. Abordagem sistêmica no mapeamento da vulnerabilidade do aqǘfero de Pereira Barreto. Geografia, Rio Claro, v. 31, n. 3, p.587-604, 2006.

HEISENBERG, W. Física e Filosofia. Brasília: Ed. Universidade de Brasília, 1981. 149p.

HESSEN, J. Teoria do conhecimento. Coimbra: A. Amado, 1968. 206p.

HUGGETT, R. J. Dissipative Systems: implications for geomorphology. Earth Surface Process Landforms, v. 13, p. 45-49, 1988.

JAPIASSU, I. Interdisciplinaridade e patologia do saber. Rio de Janeiro: Imago, 1976. 220p.

KOLARS, J. F.; NYSTUEM, J. D. Physical geography: environment and man. New York: McGrall-Hill, 1975. 344p.

LAKATOS, I.; MUSGRAVE, A. A crítica e o desenvolvimento do conhecimento. São Paulo: Cutrix; Ed. da Universidade de São Paulo, 1979. 343p.

LUZZI, R.; VASCONCELLOS, A. R. Algumas considerações sobre a complexidade, auto-organização e informação. Campinas: Unicamp, 1999. 108p.

MATOS, S, H. V. L. O paradigma da complexidade aplicado ao estudo da estabilidade em sistemas geomorfológicos. In: ENCONTRO NACIONAL DA ANPEGE, 5., 2003,
Florianópolis. Anais... p. 2570-2580.

MATURANA, H. Estratégias cognitivas. In: MORIN, E.; PIATTELLI-PALMARINI, M. A unidade do homem. v. 2. São Paulo: Cultrix; Ed. USP, 1978, p. 148-171. 1997. 350p.

A ontologia da realidade. Belo Horizonte: UFMG, MATURANA, H., VARELA, F. A árvore do conhecimento. São Paulo: P. Athenas, 2001. 283p.

MONTEIRO, C. A. F. Derivações antropogênicas dos geossistemas terrestres no Brasil e alterações climáticas. Perspectivas urbanas e agrárias ao problema da elaboração de modelos de avaliação. In: SIMPÓSIO SOBRE A COMUNIDADE VEGETAL COMO UNIDADE BIOLÓGICA, TURÍSTICA E ECONÔMICA. ACIESP, 15. 1978, São Paulo. Anais... São Paulo: Secretaria da Cultura, Ciência e Tecnologia. Academia de Ciências do Estado de São Paulo, 1978. 43p.

. Clima e excepcionalismo: conjecturas sobre o desenvolvimento da atmosfera como fenômeno geográfico. Florianópolis : Ed. da UFSC, 1991. 233p.

. Geossistema: a história de uma procura. São Paulo: Contexto, 2001, 127p.

MORIN, E. A inteligência da complexidade. São Paulo: Petrópolis, 2000. 263p.

O método 3: conhecimento do conhecimento. Porto Alegre: Sulina, 1999. 258p.

320p.

O método 4: as idéias. Porto Alegre: Sulina, 2001.

. O método 1: a natureza da natureza. Porto Alegre:

Sulina, 2002. 480p.

OLIVER, J. E. Perspective on applied physical geography. North Scituate, Max.: Duxbury Press, 1977. 315p.

PENTEADO ORELLANA, M. Metodologia integrada no estudo do meio ambiente. Geografia, Rio Claro, v. 10, n. 20, p. 125-148, 1985.

PESSOA JUNIOR, O. Auto-organização e complexidade: uma introdução histórica e crítica. Disponível em: <http:// www.fflch.usp.br/df/opessoa/AO\&C-text.pdf >. Acesso em: 15/ 11/2006.

PHILLIPS, J. D. Deterministic uncertainty in Landscape. Earth Surface Process Landforms, v. 19, p. 389-405, 1994.

Self-organization and landscape evolution. Progr. Phys. Geog., v. 19, n. 3, p. 309-321, 1995.

PRIGOGINE, I.; STENGERS, I. O fim das certezas, [S.I.]: 
Ed. Unesp, 1996. 199p.

PRIGOGINE, I. Do ser ao devir. São Paulo: Ed. Unesp; Belém: Ed. UFPA, 2002. 85p.

SALES, V. C. Geografia, sistemas e análise ambiental: abordagem crítica. GEOUSP - Espaço e Tempo, São Paulo, n. 16, p. 125-141, 2004.

SANTOS, B. S. Um discurso sobre as ciências. Porto: Afrontamento, 1998. 58p.
SOTCHAVA, V. B. O estudo de geossistemas. Métodos em Questão, São Paulo: IG-USP, n. 16, 52p., 1977.

TIEZZI, E. Tempos históricos e tempos biológicos: a Terra ou a morte: os problemas da nova ecologia. São Paulo: Nobel, 1988. 204p.

VITTE, A. C. A terceira crítica kantiana e a sua influência no moderno conceito de Geografia Física. GEOUSP - Espaço e Tempo, São Paulo, n. 19, p. 33-52, 2006.

WIENER, N. Cibernética e sociedade. São Paulo: Cultrix, 1954. 190p. 